\title{
THE INFLUENCE OF A 7-WEEK PREPARATORY PERIOD ON HORMONAL AND METABOLIC RESPONSES IN SOCCER PLAYERS
}

\author{
Metabolic and hormonal response to training
}

\author{
BENEDYKT H. OPASZOWSKI ${ }^{1,3}$, ZBIGNIEW TYC ${ }^{2}$, ZBIGNIEW OBMIŃSKI ${ }^{1}$, \\ TOMASZ DANIELIK ${ }^{2}$, MARCIN KORKUĆ ${ }^{2}$, BARBARA DŁUGOŁĘCKA ${ }^{3}$ \\ ${ }^{1}$ Institute of Sport in Warsaw, Department of Endocrinology \\ ${ }^{2}$ The Josef Pilsudski University of Physical Education in Warsaw, Department of Sporting Games \\ ${ }^{3}$ The Josef Pilsudski University of Physical Education in Warsaw, \\ The Faculty of Physical Education and Sport in Biała Podlaska, \\ Department of Physiology and Biochemistry
}

\author{
Mailing address: Benedykt H. Opaszowski, Faculty of Physical Education and Sport, \\ 2 Akademicka Street, 21-500 Biała Podlaska, tel.: +48 8334288 27, fax: +48 833428800 , \\ e-mail: benedykt.opaszowski@insp.waw.pl
}

\begin{abstract}
Introduction. The aim of the study is to evaluate the metabolic and hormonal response of soccer players to maximum effort (test for determining anaerobic threshold changes - PPA) carried out under field conditions within a training cycle, which included a preparation period of about 7 weeks. Materials and methods. In blood samples of the 20 subjects the concentrations of lactate was determined, (LA) in whole blood, also including cortisol (C), testosterone (T) and growth hormone (GH) in blood plasma, during a running exercise performed according to the formula for determination of PPA. The heart rate (HR) was recorded during the running exercise. Threshold speed was determined based on OBLA. The tests were carried out twice: at the beginning and at the end of the seventh week preparatory period. Results. The training increased the threshold speed by an average of $0.4 \mathrm{~m} / \mathrm{s}$, lower concentrations of LA during the second test and less severe changes in HR. Endurance of the tested athletes increased at more favourable hormonal response with respect to cortisol and GH. The endurance component in the training, in the $2^{\text {nd }}$ test resulted in lower resting testosterone levels, which did not affect the metabolic balance. The ratio of testosterone to cortisol (T/C), its growth after the period of training, showed a more stable anabolic-catabolic balance, which justifies the validity of the training assumptions in this period. Conclusions. The study confirmed the usefulness of metabolic-endocrine indicators in the monitoring the physiological response of athletes to exercise, as well as beneficial changes in the process of adaptation of bodies of athletes subjected to training.
\end{abstract}

Key words: soccer, training, alternating anaerobic threshold, lactate, hormones

\section{Introduction}

Rational selection of physical burden in training is essential in the process of physiological adaptation to effort during the competition. Too small and too large biological burden to the athlete's body during training has a negative impact on the training process and, consequently, causes deterioration of results. This also includes the game of soccer, which is due to the metabolism of the tissue, the nature of energy processes and the duration thereof, belongs to the group of endurance disciplines/endurance efforts, which utilise the energy potential as well as aerobic and anaerobic potential [1, 2, 3, 4]. During a game, in each case of a "speed up" or acceleration, the processes anaerobic energy contribution, followed by moments of increased oxygen consumption, or aerobic energy mobilization prevails. The long lasting system of league games requires players to be well prepared, both, in terms of strength (general fitness) and speed. Furthermore, high exercise capacity is deter- mined by biological substrate of high-endurance preparation and exercise tolerance, which, based on technical and tactical preparation determines the success of sports teams. On the other hand, an excessive emphasis on endurance training can have an impact on the speed of a player during games. Hence, the purpose of training during general preparation is to attain the optimal level of strength to then be able to build a player's speed.

One of the systems regulating exercise metabolism is the endocrine system, and its impact on the mobilisation and utilisation of energy substrates during muscular work related to the exercise of various structure/form and burdens. Exercise is a potent physiological stimulus, which results in release of hormones, including cortisol, testosterone, growth hormone, catecholamines [5, 6, 7, 8, 9, 10,11]. Hormone secretion is increased when exercise duration and intensity have reached a certain level.

Data from the literature confirm the relationship between 
high lactate metabolic acidosis, renal acid-base balance of blood and the response of the endocrine system. Thus, the magnitude of the hormonal response to exercise (training), exercise stress level can only be determined by concentration of certain hormones. The magnitude of hormonal response may represent the biological burden of the training work, while changes in levels of some hormones can provide objective information about the biological effects of the training and competition burdens applied [12, 13, 14, 15, 16, 17, 18]. The magnitude of hormonal reactions, metabolic imbalance may indicate the presence of, on the one hand, the fact of fatigue and overtraining [5, 19, 20], on the other hand, it may indicate low efficiency of the training stimuli used in the process of increasing exercise tolerance.

Prolonged physical strain during a game requires players to be well prepared in terms fitness riders and motoric efficiency. Also, the excitement accompanying sporting competition is based on hormonal reactions, which do not always have a positive effect. Excessive mental stimulation can result in rapid build-up of fatigue, it can inhibit (through reduction of secretory reserves) mechanisms stimulating the mobilisation of energy substrates [21,22].

The literature describes how to evaluate the effectiveness of training period of athletes of various disciplines. For this purpose, we often use running with a gradually increasing speed until the runner refuses to go on (maximum test). Measurements of lactate in the blood during this exercise allow us to specify the current Anaerobic Threshold Change (PPA), and thus the degree of adaptation to endurance efforts, which in the case of soccer players varies greatly in various periods of the annual training cycle [23]. In addition, the physiological parameter, another important response also includes that of the endocrine system, which is responsible for mobilizing energy for the purpose of exercise test, as well as the promptness of post-workout restitution. This assessment can be made on the basis of post-workout changes in concentrations of hormones, including catabolic and anabolic cortisol hormones, testosterone and growth hormone. Such comprehensive tests, before and after the period of training have never been conducted on soccer players. The aim of this study was to evaluate the course of adaptation of soccer players after 7 weeks of training, based on comprehensive fitness and hormonal tests, conducted before and after the period of training.

\section{Material and methods}

20 players participated in the research - they were payers of a $3^{\text {rd }}$ Division soccer club (age 23.6 \pm 3.9 years; height $177,7 \pm 6,4 \mathrm{~cm}$; body mass $75,3 \pm 8,53 \mathrm{~kg}$, BMI 23,7 $\pm 1,9$ ) twice: the first test took place on 16 January, and the second one on 5 March. The tests related to the preparatory period (about 7 weeks), during which the training included general motoric preparation with emphasis on the development of endurance. In terms of cyclicity of training this was the winter preparation period, a sub-period of general preparation. During this period 25 training units of total duration of 1,696 minutes were held. The general characteristics of the training is described by the following variables: a) coordination $195 \mathrm{~min}$, b) strength of $120 \mathrm{~min}, \mathrm{c}$ ) agility $81 \mathrm{~min}, \mathrm{~d}$ ) jumping ability $6 \mathrm{~min}$, e) dynamic strength $10 \mathrm{~min}$ f) tactics $57 \mathrm{~min}, \mathrm{~g}$ ) speed $10 \mathrm{~min}$; h) aerobic endurance $274 \mathrm{~min}$ i) technique $466 \mathrm{~min}$ j) mixed endurance $168 \mathrm{~min}, \mathrm{k}$ ) general development warm-up $120 \mathrm{~min}$. In addition, 12 control matches were played. In general, the balance of aerobic stress time accounted for about 33\%, speed and strength elements accounted for about $8.7 \%$, while the remaining time included technique, tactical preparation and control matches.

In natural conditions (on a soccer pitch, an elliptical path with a length of $250 \mathrm{~m}$ ) a speed exercise test was performed according to the formula for determination of anaerobic threshold changes (PPA), i.e. increased running speed of $0.4 \mathrm{~m} / \mathrm{s}$, starting at 2.8 speed $\mathrm{m} / \mathrm{s}$. In both periods the test effort was performed in the morning, between 9:30 and 11:30 AM. Table no. 1 shows the outline of the running tests applied in the study [2].

Table 1. Outline of the running test, including running speed at a given burden levels, the time taken to run $250 \mathrm{~m}$, the number of repetitions and the total running time for a given level of burden

\begin{tabular}{|c|c|c|c|c|}
\hline $\begin{array}{c}\text { Burden } \\
\text { level }\end{array}$ & $\begin{array}{c}\text { Running speed } \\
{[\mathrm{m} / \mathrm{s}]}\end{array}$ & $\begin{array}{c}\text { Time taken } \\
\text { to run 250 m } \\
{[\mathrm{min} ; \mathrm{s}]}\end{array}$ & $\begin{array}{c}\text { Number } \\
\text { of repetitions }\end{array}$ & $\begin{array}{c}\text { Total } \\
\text { running time } \\
{[\mathrm{min} ; \mathrm{s}]}\end{array}$ \\
\hline 1. & 2.8 & $1 \mathrm{~min} 29 \mathrm{~s}$ & $3 \mathrm{x}$ & $4 \mathrm{~min} 27 \mathrm{~s}$ \\
\hline 2. & 3.2 & $1 \mathrm{~min} 18 \mathrm{~s}$ & $3 \mathrm{x}$ & $3 \min 54 \mathrm{~s}$ \\
\hline 3. & 3.6 & $1 \min 09 \mathrm{~s}$ & $4 \mathrm{x}$ & $4 \min 36 \mathrm{~s}$ \\
\hline 4. & 4.0 & $1 \min 03 \mathrm{~s}$ & $4 \mathrm{x}$ & $4 \min 12 \mathrm{~s}$ \\
\hline 5. & 4.4 & $0 \min 57 \mathrm{~s}$ & $4 \mathrm{x}$ & $3 \min 48 \mathrm{~s}$ \\
\hline 6. & 4.8 & $0 \min 52 \mathrm{~s}$ & $5 \mathrm{x}$ & $4 \min 20 \mathrm{~s}$ \\
\hline 7. & 5.1 & $0 \min 48 \mathrm{~s}$ & $5 \mathrm{x}$ & $4 \min 00 \mathrm{~s}$ \\
\hline
\end{tabular}

The subjects were asked to perform the test to the best of their current fitness capabilities. Capillary blood was taken from the subjects' fingertips prior to the running test, in 30 to 40 seconds intervals between individual burden levels, as well as after the tests. The heart rate (HR) was recorded continuously using sporttesters made by Polar Finland. The concentration of LA in the blood was tested using the set of DR LANGE (GERMANY). Based on the relationship between the concentration of LA and the running speed the threshold speed was determined (VPPA). Blood samples for hormonal marking in the both tests, taken before the actual performance of the test $(15 \mathrm{~min})$ and after $(3 \mathrm{~min})$ were centrifuged and then frozen (at $-20^{\circ} \mathrm{C}$ ) and stored until the time of further analysis. Concentration levels of cortisol (C), testosterone $(\mathrm{T})$ and growth hormone $(\mathrm{GH})$ in all samples were determined according to the enzyme immunoassay method (ELISA) using the DRG sets (GERMANY) in a single analysis. The anabolic-catabolic balance was determined using the indicator showing the concentration of $\mathrm{T} / \mathrm{C}$ ratios according to the following formula: $\mathrm{T} / \mathrm{C}=$ testosterone $(\mathrm{nmol} / \mathrm{l})$ : cortisol (nmol / l) $\mathrm{x}$ 100. Statistical analysis was performed using statistical package STATISTICA version 9.0. The analysis included mean values \pm SD, Student's t-test for dependent characteristics and comparison of average post-hoc test (LSD). The study report was approved by the Ethics Committee of the Institute of Sport, and the players having been informed of the potential risks, agreed to participate in tests.

\section{Results}

As far as body mass of the tested players is concerned, we noticed an average decrease in this parameter by approximately $1 \mathrm{~kg}$, i.e. from $75,5 \pm 8,7$ in the first test, to $74,5 \pm 7,9(\mathrm{P}<0,05)$ in the second test. Table no. 2 presents concentrations of lactate (LA) determined at rest before the running, and after the running of individual distances at set speeds. The resting values fall within the physiological limits, while the subsequent speeds indicate progression of the concentration of lactic acid in the blood to maximum levels at the end of the exercise test. This includes changes in LA in the function of the running speed in terms of both tests. It is worthwhile to emphasise the lower concentrations of lactate at the same speed in the test. Signifi- 
cant $(\mathrm{P}<0,05)$ differences appeared at speeds of $4 \mathrm{~m} / \mathrm{s}$ and higher. Additionally, the maximum concentration of LA was lower than the final value from the first test (respectively $12,3 \pm 2,9$ and $16,1 \pm 3,2 \mathrm{mmol} / \mathrm{l}$ ) (Tab. 2). The second test was concluded at a higher speed than the first one. This also implies longer total running time at lower concentrations of lactate. The test results indicate an increase in endurance of the tested athletes following the period of general preparation. These changes are confirmed by the threshold running speed (VPPA), which during the first test of the group was $3,24 \pm 0,28 \mathrm{~m} / \mathrm{s}$, and after the training cycle it significantly increased $(\mathrm{P}<0,05)$ to $3,66 \pm 0,32 \mathrm{~m} / \mathrm{s}$ (Fig. 1). Fig. 2 depicts the course of heart rate (HR) changes in the function of running, during the first and the second test. As expected, each increase in speed was accompanied by an increase in HR up to limit values - i.e. until the exercise test was stopped. Knowing the threshold speed at $4 \mathrm{mmol} / \mathrm{l}$ we can also determine the threshold heart rate (HRPPA). This is a valuable piece of information for sporting practice, as it allows for precise determination of threshold values that are optimal for payers' aerobic fitness and endurance. Greater threshold speed implies better endurance. The threshold value of heart rate in the first test was at an average of $174,9 \pm 13,79$ beats $/ \mathrm{min}$. As a result of the training it fell to $170,8 \pm 13,67$ beats/min. (Fig. 2). Also changes in HR in the function of running speed were at a level lower by an average of approximately 4-6 beats/min. (Fig. 2). The lowering of effort HR is a symptom of so called post training vagotonia and indicates positive adaptation of the cardio vascular system. Table no. 3 shows the hormonal response to a stimulus exercise in the applied running test "to the limit". In the case of testosterone, cortisol and growth hormone $(\mathrm{GH})$ we observed increases in their levels after the exercises, both, in the case of the first test as well as the second one. In the first test, significant $(\mathrm{P}<0.05)$ post-exercise increases in the concentrations were observed in the case of growth hormone and testosterone. With respect to testosterone and cortisol the second test revealed lower values as compared to the first test. The post-exercise increase in cortisol levels was small (Table 3). The training, which utilised endurance burdens revealed smaller testosterone levels at rest, but also lower cortisol secretion. In the case of the growth hormone $(\mathrm{GH})$ the post exercise values were similar, and were approximately $28 \mathrm{ng} / \mathrm{ml}$. Significantly smaller was the increase in GH concentration after exercise in the second test. In the first test this value was at an average of about $26 \mathrm{ng} / \mathrm{ml}$, while in the second test it was approximately $20 \mathrm{ng} / \mathrm{ml}$. The differences are statistically significant at $\mathrm{p}<0.05$ (Table 3). The anabolic-catabolic rate (T/C) calculated for pre-test value in the first test was at an average of $3.2 \pm 1.59$, whereas in the second test it significantly increased $(\mathrm{P}<0.05)$ to $4.2 \pm 1.46$. This result emphasises the stable anabolic-catabolic balance prior to the period of specialist preparation as well as after the training cycle.
Table 2. Concentration of lactic acid (LA) in the blood and the heart rate (HR) during the test determining anaerobic threshold changes with increasing running speed $(\mathrm{m} / \mathrm{s})$ in the $1^{\text {st }}$ and $2^{\text {nd }}$ test (average $\pm \mathrm{SD}$ )

\begin{tabular}{|c|c|c|c|c|c|c|c|c|}
\hline \multirow{2}{*}{$\begin{array}{c}\text { Test } \\
\text { number }\end{array}$} & \multicolumn{8}{|c|}{ LA (mmol/l) } \\
\hline & $\begin{array}{c}\text { Before } \\
\text { running }\end{array}$ & $2.8 \mathrm{~m} / \mathrm{s}$ & $3.2 \mathrm{~m} / \mathrm{s}$ & $3.6 \mathrm{~m} / \mathrm{s}$ & $4.0 \mathrm{~m} / \mathrm{s}$ & $4.4 \mathrm{~m} / \mathrm{s}$ & $4.8 \mathrm{~m} / \mathrm{s}$ & $5.2 \mathrm{~m} / \mathrm{s}$ \\
\hline \multirow{2}{*}{$1 \mathrm{x}$} & 1.5 & 3.3 & 3.7 & 5.6 & 8.6 & 12.7 & 16.1 & \\
\hline & \pm 0.4 & \pm 0.9 & \pm 1.1 & \pm 1.5 & \pm 2.6 & \pm 3.3 & \pm 3.2 & \\
\hline \multirow{3}{*}{$2 \stackrel{x}{S D}$} & 1.5 & 2.4 & 2.4 & 3.8 & 5.4 & 8.5 & 11.4 & 12.3 \\
\hline & \pm 0.4 & \pm 0.6 & \pm 0.8 & \pm 1.5 & $\pm 2.2^{*}$ & $\pm 3.1^{*}$ & $\pm 2.8^{*}$ & \pm 2.9 \\
\hline & \multicolumn{8}{|c|}{ HR (sk./min) } \\
\hline \multirow[b]{2}{*}{$s$} & 89.8 & 157.8 & 171.5 & 183.4 & 189.5 & 195.9 & 192.7 & \\
\hline & \pm 11.3 & \pm 10.4 & \pm 8.3 & \pm 8.1 & \pm 8.7 & \pm 7.7 & \pm 4.6 & \\
\hline \multirow[b]{2}{*}{ SD } & 88.0 & 143.5 & 155.5 & 169.9 & 179.3 & 186.0 & 191.3 & 195.8 \\
\hline & \pm 12.1 & $\pm 10.0^{*}$ & $\pm 10.0^{*}$ & $\pm 8.6^{*}$ & $\pm 9.5^{*}$ & $\pm 9.5^{*}$ & \pm 6.8 & \pm 14.8 \\
\hline
\end{tabular}

* value significantly $(\mathrm{P}<0.05)$ lower than that obtained in the $1^{\text {st }}$ test

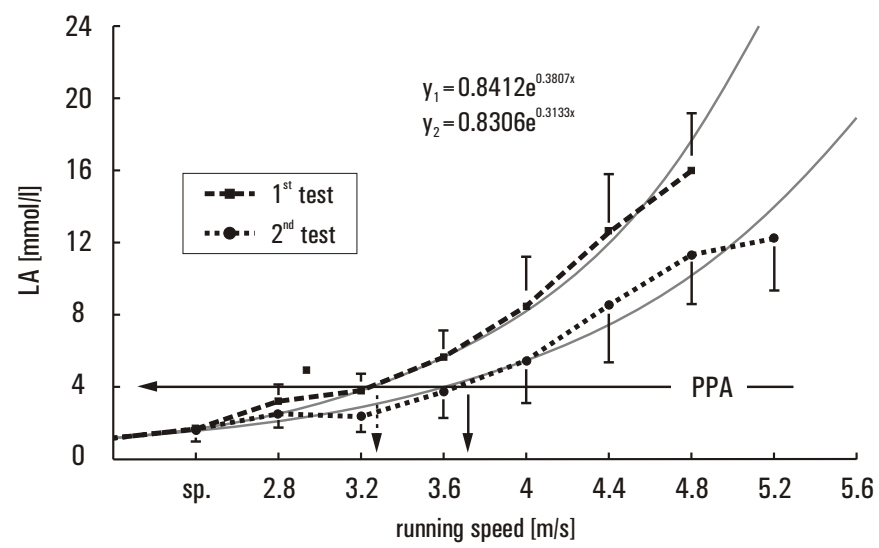

Fig. 1. Curve showing lactate concentration (LA) in the blood of soccer players as a function of running speed during determination of anaerobic threshold changes (PPA) in the $1^{\text {st }}$ and $2^{\text {nd }}$ test (mean \pm SD). The arrows represent threshold speeds.

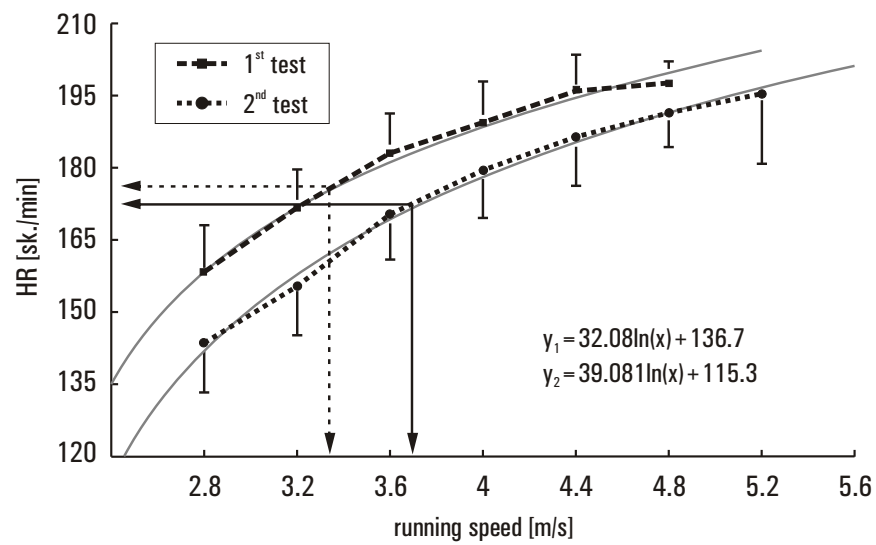

Fig. 2. Heart rate (HR) curve of soccer players as a function of running speed during determination of anaerobic threshold changes (PPA) in the $1^{\text {st }}$ and $2^{\text {nd }}$ test (mean $\pm S D$ ).

The arrows represent threshold speeds. 
Table 3. Concentration of testosterone (T), cortisol (C) and growth hormone $(\mathrm{GH})$ in the plasma and values of anabolic-catabolic indicator $(\mathrm{T} / \mathrm{C})$ before and after the running test of soccer players in the $1^{\text {st }}$ and $2^{\text {nd }}$ test (average \pm SD)

\begin{tabular}{|c|c|c|c|c|c|c|c|c|}
\hline \multirow{2}{*}{$\begin{array}{c}\text { Test } \\
\text { number }\end{array}$} & \multicolumn{2}{|c|}{$\begin{array}{l}\text { Testosterone } \\
\text { (nmol/I) }\end{array}$} & \multicolumn{2}{|c|}{$\begin{array}{l}\text { Cortisol } \\
\text { (nmol|ll) }\end{array}$} & \multicolumn{2}{|c|}{$\begin{array}{c}\text { GH } \\
\text { (ng/ml) }\end{array}$} & \multicolumn{2}{|c|}{$T / C$} \\
\hline & before & after & before & after & before & after & before & after \\
\hline \multirow{2}{*}{1} & 18.3 & 22,5 & 555.3 & 596.7 & 2.7 & 28.7 & 3.2 & 3.8 \\
\hline & \pm 6.16 & $\pm 8.56^{\mathrm{a}}$ & \pm 173.95 & \pm 155.18 & \pm 3.69 & $\pm 16.23^{\mathrm{a}}$ & \pm 1.59 & \pm 1.32 \\
\hline \multirow[b]{2}{*}{ SD } & 15.1 & 20.8 & 374.1 & 401.1 & 7.9 & 28.3 & 4.2 & 5,2 \\
\hline & \pm 3.08 & $\pm 6.83^{\mathrm{a}}$ & $\pm 91.21^{\circ}$ & $\pm 129.63^{c}$ & $\pm 10.35^{b}$ & $\pm 16.07^{\mathrm{a}}$ & $\pm 1.46^{b}$ & $\pm 1.43^{a b}$ \\
\hline
\end{tabular}

value significantly $(\mathrm{P}<0.05)$ higher than the data "before" exercise;

value significantly $(\mathrm{P}<0.05)$ higher than the date obtained in the $1^{\text {st }}$ test; value significantly $(\mathrm{P}<0.05)$ lower than the data obtained in the $1^{\text {st }}$ test

\section{Discussion}

The presented tests cover the period of general preparation, which aims to increase exercise tolerance through the use of endurance effort based on aerobic energy processes. The proposed test for determination of anaerobic threshold changes performed during the first test gave practical evidence to determine the optimal intensity of running training with the goal of increased aerobic fitness, and repeating the test after the training cycle verifies the correctness of the training assumptions. The use of hormone determinations in the test, which will evaluate the status of androgen-glucocorticoid, gives a broader picture of the changes induced by physical training in the development of mechanisms to regulate the use of renewable energy and the direction of effort metabolism. In addition, maintaining an optimum anabolic-catabolic balance seems to be a necessary condition for the development of adaptation to exercise and sports training. This includes the secretion relationship between cortisol and testosterone and the maintenance "secretory reserve" of the pituitary gland in relation to growth hormone, which has a strong anabolic effect [5, 7, 23, 24].

As expected, the results of the running exercise (test 2) showed improved in aerobic endurance, as evidenced by the increase in the threshold speed. The lactate curve shifted to the right, i.e. in the direction of greater speed at which the players finished the test. This also happened at lower post exercise blood lactate concentration. This clearly shows an increase in the efficiency of aerobic processes. The proof of this is the decline in the heart rate (HR) during exercise at similar speeds in the second test. This is valuable information for the practice of sport, which emphasises cardiovascular adaptation to exercise, for example by increasing the volume (SV) and cardiac output, it provides a basis for greater burdens [3, 25, 26]. The exercise effort resulted in an increase in testosterone, in the first as well as the second test by an average of $4.2 \mathrm{nmol} / \mathrm{l}$ in the first test and $5.7 \mathrm{nmol} / \mathrm{l}$ in the second. What needs to be emphasised here are the lower concentrations of testosterone during the second test identified at rest before the race (an average of 18\% for the group). This may suggest possible effect of the endurance training applied in this period on the androgen response. Strength and speed training stimulates the secretion of testosterone through a significant secretion of pituitary hormones (LH and FSH) stimulated by the hypothalamic GnRH (gonadotropin-releasing hormone). In the case of training with significant endurance component we can observe attenuation of the androgenic response [14, 16, 27].

Significant stimulation of androgen through physical exercise (significant increase in testosterone levels) indicates a high possibility of regeneration and a tolerance reserve to substantial training burdens, and provides the basis for speed training and strength. Stable androgenic status (high concentrations of testosterone without significant changes) provides a basis for the development of payers' "sporting aggressiveness" and the ability to focus more on the technical and tactical training [4, 10, 15]. One needs to bear in mind that low levels of testosterone in juveniles translate into "less energy" to work and engage in competitive sportsmanship. In the assessment of hormonal response one also needs to remember the reverse situation, i.e. enhanced reaction, which may indicate a metabolic imbalance due to over-stimulation of the "hypothalamic-pituitary-gonadal" axis, which could also adversely affect the restitution after training or competition [5, 12, 19]. Excessive stimulation can affect the reactions/performance of a player during a game. In the light of the results, an increase testosterone levels in the range of 4.0-8.0 nmol/l should be assumed to be a favourable hormonal response to a defined physical exercise.

Changes in the concentration of cortisol in the blood under the influence of physical activity described in the literature are multidirectional and their interpretation is fully complementary and clear. Discussions in the literature include increases in cortisol levels in the blood, its reduction as well as no change whatsoever [13, 7, 8, 23]. An important role in the magnitude and direction of hormonal response to exercise is played by the power/intensity of the exercise as well as its duration. It was also found that exercise increases the rate of its disappearance in the blood. A lot of data suggests that an increase in the level of cortisol in the blood occurs when the exercise effort is very significant, and the duration of the exercise is more than 20-30 minutes. It is assumed that an increase in the concentration of cortisol in blood is a reaction to the stress caused by emotional arousal which accompanies the physical effort. Metabolic changes (increased lactic acid), abnormal acid-base balance of blood (decrease in $\mathrm{pH}$ ), insufficient supply of oxygen and depletion of carbohydrate reserves may lead to increased levels of cortisol in the blood [5, 19, 21]. This hormone is characterised by daily rhythm, with the largest values present in the morning and lower levels at night. In the case of people who go to bed late, this rhythm can be shifted. The rhythm of cortisol is affected by such factors as food, physical work (training) and stress. Under conditions of strong stress response, fatigue and overtraining we can observe excessive adrenal response. Its resting build up during training cycle may indicate the severity of the catabolic processes (decay), lack of full restitution after the training session. Adaptation of the body to increased training burdens is reflected in more efficient regulatory mechanisms, neural as well as hormonal. One must develop high capacity to respond to large, also including increasing of the "secretory reserve" of the adrenal glands, i.e. the additional cortisol secretion. It is assumed that the adaptation endurance training is characterised by decrease in the secretion of cortisol [8, 12, 16]. In our research the concentration of cortisol at rest was $555 \mathrm{nmol} / \mathrm{l}$ (before exercise) in the first within test, and after the running test it increased to $596 \mathrm{nmol} / \mathrm{l}$, i.e. about $7 \%$. In the second test the post exercise increase in cortisol was also approximately 7\%, but at lower concentrations. One would therefor assume that the increase in threshold power/speed (PPA) under the influence of exercise causes a decreased adrenal response (smaller secretion of cortisol). Increased availability of oxygen to the working muscles reduces the hormonal response in the light of cortisol changes, and thus is an expression of a greater resistance to exercise stress. This also underlines the fact of smaller excitation of the "hypothalamic-pituitary-gonadal" axis. High cortisol values (on average) are typical for sports groups, which is also associated with the season of the year and possibly the series of training (poor endurance preparation of athletes). Testosterone has anabolic effects, which is manifested mainly by an increase in the mass of muscles. It also 
works in a counter-regulatory way with respect to active muscles reacting to cortisol, which has a catabolic effect (effect on muscle proteins degradation). The relationship between these two hormones is referred to a metabolic balance. They have become the basis of anabolic-catabolic rate $(\mathrm{T} / \mathrm{C})$ used in sport to evaluate the biological effects of training $[3,5,11]$. Balance between anabolic and catabolic processes in the body seems to be the basis for achieving the "optimum" sports training. Decrease of this variable $(\mathrm{T} / \mathrm{C})$ below 3.0 may indicate severity of catabolic processes (too great training burden) and lack of full post training restitution. In the case of our tests the average value of the index before the running in the first was 3.2, while in the second test it was significantly higher-i.e. 4.2. In the first and the second test, the strain caused increases in the value of anabolic-catabolic rate, to 3.8 in the first test (up 18\%) to 5.2 in the second test (up 24\%). Its low value, i.e., $<3$, and a decrease after the exercise may indicate lack of adequate training, the occurrence of fatigue, lack of rest or an improper diet. Exercise tolerance may be low and limited. In our study we observed a favourable reaction after the training cycle [26, 27, 28, 29].

The stimulating effect of growth hormone in the body is takes place through polypeptides growth factors (IGF - insulinlike growth factor) called the somatomedins and secreted by the liver and other tissues in response to the action of GH. Its secretion during the day is pulsating, i.e., GH is secreted in discrete pulses 6-12 times a day, with its acrophase observed during deep sleep, i.e., after about 1-2 hours of sleep. Its secretion can be stimulated by protein intake, hypoglycaemia, pregnancy, mental stress and physical exercise [6, 12, 24]. GH levels at rest are sometimes undetectable using the DRG set, while its concentration usually falls in the range of 0.2 to $3.0 \mathrm{ng} / \mathrm{ml}$. GH secretory capabilities decline with age. The greatest GH secretion, as described above, is observed during sleep, particularly including deep sleep. Intense exercise can affect its nocturnal secretion, decreasing the amplitude of secretory cycles and its peak value $[9,10,13]$. It was observed that exhaustive physi$\mathrm{cal} /$ sports training, affects the secretion of GH during the sleep (reducing the amplitude of the secretory cycle and its peak value). At the same time, the relationship between the sleep (especially the deep phase) and the largest discharge in the night and day cycle has not been explained yet. The explanation for this relationship may be particularly important for the practice of sport, because proper sleep with relevant GH relationship is of fundamental importance in the processes of regeneration (renewal) of intensely training players. Stress, which inherently associated with exercise, may cause an increase in $\mathrm{GH}$ secretion. Increase in its concentration in the blood can be observed even before the effort. It is reported that the $\mathrm{GH}$ response to relatively comparable burden is lower in the case of who exercise, than in the case of those who do not exercise. During exercise the secretion of the growth hormone is regulated by the availability of glucose. Greater concentrations of $\mathrm{GH}$ are observed during exercise of greater intensity. Also the duration of the exercise results in an excessive reaction of the growth hormone $[6,22,20]$. The efforts made by the tested players in both tests resulted in an increase of GH to a similar mean value (approximately $28 \mathrm{ng} / \mathrm{ml}$ ). The absolute post exercise increase in the concentration was lower in the second test, despite greater effort, which can be regarded as a manifestation of adaptation resulting from the training. What is surprising is the almost 3-times higher pre-exercise concentration of this hormone after the period of training. In the literature there is no information about such behaviour of $\mathrm{GH}$ at rest following a period of training. Assuming that the growth hormone is involved in the process of lipolysis, i.e. the release of free fatty acids (FFA) into circulation, which are an energy substrate utilised during exercise of aerobic nature of the efforts, one can suggest that elevated levels of $\mathrm{GH}$ before exercise can also be a manifestation of the metabolic adaptation after the period of training, as before the exercise, it increases the amount of energy substrate in the circulation before work. However, this hypothesis requires further verification in an experiment marked as FFA. Higher post training GH levels at rest, which is an anabolic hormone, may also suggest that the actual anabolic-catabolic balance is shifted more towards the reconstruction of structural proteins than one might expect only on the basis of comparisons of resting indicators T/C in the first (3.2) and the second test (4.2). Analysis of the post training and at rest changes in the anabolic-catabolic rate provides basis for a new approach to the metabolism of endogenous proteins, which depends on the three tested hormones - i.e. testosterone, cortisol and growth hormone.

The study has revealed wide differentiation of exercise abilities of athletes. Training can modulate stress responses caused by strenuous exercise. Prolonged physical activity/training changes the proportions in the use of energy substrates, hence the objective information relating to the peripheral levels (in the blood) of selected hormones emphasises their role in the regulation and adaptation to exercise. The literature talks about hormonal adaptation to chronic stress, such as e.g. sports training.

\section{Conclusions}

The conducted analysis training cycle of soccer players based on changes in selected physiological and hormonal indicators allows us to formulate following conclusions:

1. As a result of the 7 week training the payers' endurance increased, as evidenced by the significant increase in the threshold speed, lower threshold heart rate and lower lactate values at each speed level of the running test.

2. There was no breach of the androgen-glucocorticoid status, and the metabolic balance shifted as a result of the training in the direction towards dominance of anabolic processes. This is an important information for the practice of sports in the process of optimisation of training, and confirms the validity of the training assumptions made by the coach.

\section{Literature}

1. Carli, G., Bonifazi M., Lodi L., Lupo G., Martelii G.\& Viti A. (1986). Hormonal and metabolic effects following a football match. Int J Sporst Med, 7: 36-38.

2. Jastrzębski, Z. (2004). Training burdens and their impact on sporting development of soccer players and handball payers. Gdańsk: Wydawnictwo AWFiS. [in Polish]

3. Krustrup, P., Christensen J.F., Randers M.B., Pedersen H., Sundstrup E., Jakobsen M.D. et al. (2010). Muscle adaptations and performance enhancements of soccer training for untrained men. Eur. J. Appl. Physiol. 108, 1247-58.

4. Bangsbo, J., Iaia F.M. \& Krustrup P. (2007). Metabolic response and fatigue in soccer. Int J Sports Physiol Perform. 2:111-27.

5. Adlercreutz, H., Harkonen M., Kuoppasalmi K., Naveri H., Huhtaniemi, Tikkanen H. et al. (1986). Effect of training on plasma anabolic and catabolic steroid hormones and their response during physical exercise. Int. J. Sports Med., 7: 27-28.

6. Godfrey, R.J., Madgwick Z. \& Whyte G.P. (2003). The exercise-induced growth hormone in athlets. Sports Med, 33(8): 599-613.

7. Hakkinen, K. \& Pakarinen A. (1995): Acute hormonal responses to heavy resistance exercise in men and women at different ages. Int J Sports Med, 16:507-513. 
8. Hartley, L.H, Mason J.W., Hogan R.P., Jones L.G., Kotchen T.A., Mougey E.H. et al. (1972). Multiple hormonal responses to graded (prolonged) exercise in relation to physical training. J Appl Physiol, 33: 602-610.

9. Raastad, T., Bjoro T. \& Hallen J. (2000). Hormonal responses to high- and moderate-intensity strength exercise. Eur J Apel Physiol, 82: 121-128.

10. Ronsen, O., Haug E., Pedersen B.K. \& Bahr R. (2001). Increased neuroendocrine response to a repeated bout of endurance exercise. Med Sci Sporst Exerc., 33 (4):568-575.

11. Vervoorn, C., Vermulst L.J.M., Boelens-Quist A.M., Koppeschaar H.P.F., Erich W.B.M., Thijssen J.H.H. et al. (1992). Seasonal changes in performance and free testosterone: cortisol ratio of elite female rowers. Eur J Appl Physiol, 64: 14-21.

12. Bonifazi, M., Bela E., Lupo C., Martelli G., Zhu B. \& Carli G. (1998). Influence of training on the response to exercise of adrenocorticotropin and growth hormone plasma concentrations in human swimmers. Eur J Appl Physiol, 78:394397.

13. Hackney, A.C., Spinning W.E. \& Brutt B.C. (1990). Hypothalamic-pituitary-testicular axis function in endurance-trained males. Int J Sports Med, 11: 298-303.

14. Hakkinen, K., Leskinen K.L., Alen M., Komi P.V. \& Kauhanen H. (1989). Serum hormone concentrations during prolonged training in elite endurance-trained and strength-trained athletes. Eu JAppl Physiol, 59:233-238.

15. Mejri, S., Bchir F., Ragana M.C.B. \& Hamida J.B. (2005). Effect of training on GH and IGF-1 responses to a submaximal exercise in football players. Eur J Apl Physiol, 95: 496503.

16. Steinacker, J.M., Lormes W., Reissnecker S. \& Liu Y. (2004). New aspects of the hormone and cytokinine response to training. Eur J Appl Physiol, 91(4): 382-391.

17. Urhausen, A., Kullmer T. \& Kindermann W. (1987). A 7-week follow-up study of the behavior of testosterone and cortisol during the competition period in rowers. Eur J Appl Physiol, 56: 528-533.

18. Iaia, F.M., Hellsten Y., Nielsen J.J., Fernström M., Sahlin K. \& Bangsbo J. (2009). Four weeks of speed endurance training reduces energy expenditure during exercise and maintains muscle oxidative capacity despite a reduction in training volume. JAppl Physiol. 1,73-80.

19. Urhausen, A., Gabriel H. \& Kinderman W. (1995). Blood hormones as markers of training stress and overtraining. Sports Med.20(4): 251-276.
20. Opaszowski, B.H., Rojek J., Hübner-Woźniak E., Długołęcka B. \& Obmiński Z. (2007). Metabolic and hormonal response of soccer players to maximum effort performed under laboratory conditions. Rocznik Naukowy Zamiejscowego Wydziału Wychowania Fizycznego w Białej Podlaskiej, Tom XIV, 33-45. [in Polish]

21. Gordon, S.E., Kraemer W.J., Vos N.H., Lynch J.M. \& Knuttgen H.G. (1994). Effect of acid-base balance on the growth hormone response to acute high-intensity cycle exercise. JAppl Physiol,76: 821-829.

22. Goto, K., Higashiyama M., Ishii N. \& Takamatsu K. (2005). Prior endurance exercise attenuates growth hormone response to subsequent resistance exercise. Eur J Appl Physiol, 94: 333-338.

23. Kanaey, J.A., Weltman J.Y., Pieper K.S., Weltman A. \& Hartman M.L. (2001). Cortisol and growth hormone responses to exercise at different times of day. J Clin Endocrionol Metab., 86(6): 2881-2889.

24. Mejri, S., Bchir F., Ben Rayana M.C., Ben Hamida J. \& Ben Slama C. (2005). Effect of training on GH and IGF-1 responses to a submaximal exercise in football players. Eur J Appl Physiol. 95:496-503.

25. Krustrup, P., Nielsen J.J., Krustrup B.R., Christensen J.F., Pedersen H., Randers M.B. et al. (2009). Recreational soccer is an effective health-promoting activity for untrained men. Br J Sports Med. 43, 825-31.

26. Iaia, F.M. \& Bangsbo J. (2010). Speed endurance training is a powerful stimulus for physiological adaptations and performance improvements of athletes. Scand J Med Sci Sports. 20 Suppl 2:11-23.

27. Cormack, S.J., Newton R.U., McGuigan M.R. \& Cormie P. (2008). Neuromuscular and endocrine responses of elite players during an Australian rules football season. Int $J$ Sports Physiol Perform. 3:439-53.

28. Di Salvo, V. \& Pigozzi F. (1998). Physical training of football players based on their positional rules in the team. Effects on performance-related factors. 38:294-7.

29. Hoffman, J.R., Kang J., Ratamess N.A. \& Faigenbaum A.D. (2005). Biochemical and hormonal responses during an intercollegiate football season. Med Sci Sports Exerc. 7:123741.

Submitted: April 18, 2012

Accepted: June 27, 2012 